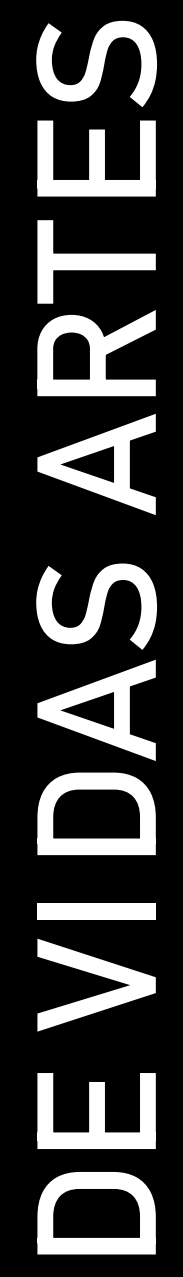

PAULA GUERRA E LÍGIA DABUL (EDS.) 


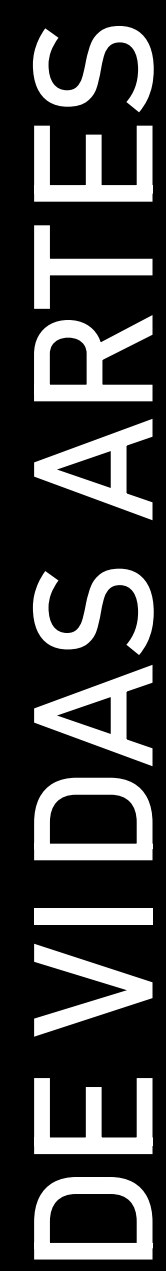

\section{PAULA GUERRA E LÍGIA DABUL (EDS.)}

Design por Irandina Afonso

Ilustração da Capa por Lua Celina

Publicado em Setembro 2019

Universidade do Porto. Faculdade de Letras

[University of Porto. Faculty of Arts and Humanities]

Porto, Portugal

ISBN 978-989-8969-18-7

Suporte: Eletrónico - Formato: PDF / PDF/A 


\title{
IV.5. "Rapper, musa, música, mulher". Empoderamento feminino e imbricações do regionalismo gaúcho na cultura hip-hop
}

\author{
IV.5. "Rapper" muse, music, woman". Female \\ empowerment and imbrications of gaucho regionalism in \\ hip-hop cullture
}

\section{Dulce Mazer}

\begin{abstract}
Resumo
O texto tem o objetivo de discutir como as rappers vêm alterando suas práticas socioculturais na cultura hip-hop, considerando a hibridação com o regionalismo gaúcho. Como principais contributos, o texto faz uma breve revisão das contribuições de mulheres para a história do rapa partir da visão feminista e repensa como as novas gerações de MCs alteram sua realidade. $O$ estudo base para as discussões foi realizado na Região Metropolitana de Porto Alegre, capital do estado gaúcho do Rio Grande do Sul (RS), entre 2014 e 2018. Os métodos do estudo foram a observação etnográfica e a pesquisa documental.
\end{abstract}

Palavras-chave: rap, mulher, cultura regional, cultura gaúcha.

\begin{abstract}
The text discusses how female rappers have been changing their socio-cultural practices in hip-hop culture, considering a hybridization with the gaucho regionalism. As key contributions, the text briefly reviews the contributions of women to the history of rap from the feminist perspective and rethinks how the new generations of MCs change their reality. The basic study for the discussions was carried out in the Metropolitan Region of Porto Alegre, capital of the state of Rio Grande do Sul, state of Rio Grande do Sul, between 2014 and 2018. The methods were an ethnographic observation and a documentary research.
\end{abstract}

Key words: rap, woman, regional culture, gaucho culture.

\section{Música e mulher: empoderamento das rappers}

Nas últimas quatro décadas, a cultura ${ }^{212}$ hip-hop vem se desenvolvendo em um conjunto de ritos, expressões e simbolismos compartilhados ao redor do mundo, mas que reserva certas particularidades em distintas regiões. Através do rap, cada vez mais popular, os hip-hoppers manifestam suas vivências,

\footnotetext{
212 Resultado da pesquisa de pós-doutorado realizada na Universidade Federal do Rio Grande do Sul, este texto apresenta reflexões sobre a cultura hip-hop na Região Metropolitana de Porto Alegre (RS - Brasil); simultaneamente, representa igualmente experiências vividas pela autora em diferentes metrópoles latino-americanas, como Buenos Aires, Bogotá e Cidade do México ao longo de suas pesquisas sobre o consumo cultural de rap.
} 


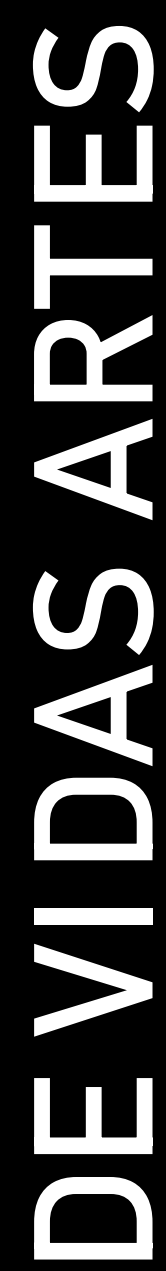

\section{PAULA GUERRA E LÍGIA DABUL (EDS.)}

Design por Irandina Afonso

Ilustração da Capa por Lua Celina

Publicado em Setembro 2019

Universidade do Porto. Faculdade de Letras

[University of Porto. Faculty of Arts and Humanities]

Porto, Portugal

ISBN 978-989-8969-18-7

Suporte: Eletrónico - Formato: PDF / PDF/A 
expectativas e opiniões em ritmo e poesia, configurando um cenário de variada produção musical. Neste sentido, rappers amadores e profissionais reorganizam a atividade artística da qual partilham saberes, acompanhando a evolução da indústria musical e fonográfica, mas igualmente explorando novas formas de produção de acordo com seu cotidiano, seu entorno socioeconômico, cuja principal fonte para criação e circulação é a Internet.

Embora consolidado, o hip-hop, como qualquer cultura, está em constante ressignificação, sobretudo quando observado a partir do viés feminista. Com a terceira onda do movimento, as culturas musicais tornaramse centrais para a universalização do conceito de mulher e feminismo, assim como foram o cerne de transformações sociais. Entre as (sub)culturas que protagonizaram mudanças nos anos 1990, os movimentos punk femininos foram fundamentais para a discussão vanguardista na arte de temas como o empoderamento feminino, a cultura do estupro, o domínio patriarcal e questões ligadas à sexualidade, entre outros. Através da cultura do "faça você mesmo" (do-it-yourself - DIY), da negação ao corporativismo industrial, a interseccionalidade era fortalecida no feminismo como chave para se pensar distintas realidades.

Classe, raça e sexualidade ganhavam contornos expressos através da música e outros componentes culturais, como vestimentas e atitudes. Como resultante do desenvolvimento histórico pós-estruturalista, as identidades, os simbolismos, os movimentos e as instituições passaram a ter suas definições borradas para a maior inclusão de mulheres. O protagonismo musical feminino buscava então dissuadir ideias de vitimização e liberação, próprias das ondas históricas anteriores. Em seu lugar, eram fortalecidas as liberdades individuais, a ressignificação da misoginia, desde a linguagem até padrões comportamentais, como novos usos para o termo "vadia" e possibilidades de assumir a sexualidade. Um olhar para a história do hip-hop, porém, revela que as MCs igualmente contribuíram para o feminismo interseccional, relacionando suas trajetórias na música às conquistas das mulheres negras.

Antes mesmo do hip-hop ganhar o mundo, despontavam junto à disco pioneiras da cadeia produtiva musical, como Sylvia Robinson, produtora da Sugar Hills Records, que apoiou a gravação de Rapper's Delight (1979), inaugurando a popularidade do rap nos Estados Unidos, e Lady B (To the beat y'all, 1979), uma das primeiras mulheres a gravar um single de Rythm and Poetry. Já nos anos 1990, figuravam queens como Roxanne Shante, Lauryn 
Hill, Missy Elliot, Lil'Kim, Foxy Brown, Ashanti e as MCs Salt-n-Pepa, que através de suas letras passavam "mensagens contraditórias", segundo Oware (2009), pois, ao passo que cantavam sobre o empoderamento feminino e a agência negra, seus maiores sucessos as auto-objetificavam, versavam sobre o consumo de álcool e drogas, assim como manifestavam o desgosto e até o ódio por suas concorrentes. Alguns autores justificam esse panorama de ambiguidades observando a "ausência das mulheres" (Reddington, 2003 e 2012) nas culturas musicais, seja nas manifestações do rock, do metal, do punk, do rap e do hip-hop. Esse seria um dos melhores exemplos da hegemonia masculina acerca da história da cultura popular (Guerra, 2017). Mas as críticas à auto-exploração da sexualidade feminina pelas rappers são limitadas, não oferecendo uma reflexão suficientemente complexa, pois desconsideram o contexto de circulação dessas mulheres. Embora certas incoerências possam ser lidas nas entrelinhas de suas poesias, essas MCs tiveram valoroso papel, não apenas por serem poucas e insistentes mulheres no concorrido mercado fonográfico da época. Elas igualmente ressignificaram a linguagem misógina do rap, apropriando-se de uma identidade bitch (vadia) e criando um novo sentido para o sexy appeal e o corpo da mulher negra. Elas abordavam a sexualidade feminina como sujeitas, não como objetos sexuais, motivando reflexões, especialmente para as negras, questionando padrões dominantes de sexualidade.

Artistas como Queen Latifah e MC Lyte, nos Estados Unidos, Cris SNJ e Negra Li, no Brasil, foram pioneiras no hip-hop feminista, quando o rap já se tornava um gênero musical de mainstream. No final da primeira década dos anos 2000 elas se converteriam nas musas transgressoras da atual geração de garotas rappers, influenciando novas práticas e modos de produção do rap contemporâneo, já não tão pautadas pelas performances sexualizadas. As estadunidenses, influenciadas pela black music, cantavam as opressões à mulher negra, tais como a violência e a carga dos trabalhos domésticos, bem como questões sobre a sexualidade, justiça, direitos e igualdade para mulheres negras. No Brasil, as rimas revelavam um sexismo artístico encontrado até os dias atuais, sobretudo quanto à competência na produção das rimas, da capacidade de improvisar no freestyle e do direito à cultura hip-hop.

Rose (1994), buscando expandir as vozes feministas para uma reflexão mais aprofundada sobre a sexualidade da mulher negra na 
sociedade estadunidense, observa modos pelas quais as rappers trabalham as narrativas contra a dominação sexual e racial, sem se opor completamente aos discursos dos rappers homens. Para Rose (1994), os temas centrais na obra de mulheres - a relação sentimental heterossexual, a atuação das MCs e a liberdade corporal e sexual - são abordados de duas maneiras. A primeira corrobora os discursos sexuais de rappers homens e a segunda dialoga com discursos sociais mais amplos, como particularmente o feminismo. Mas, para a acadêmica, os primeiros apenas refletem o profundo sexismo que perpassa a cultura nos Estados Unidos. Letras machistas são ainda parte de um machismo normalizado que domina a cultura corporativa no negócio da música. Não somente as artistas enfrentam diferenças salariais e de rendimento, mas elas têm que encarar assédios morais e sexuais diários. A desigualdade na renda, assim como os assédios, são situações comuns até mesmo na produção amadora de rap. Frequentar estúdios, por exemplo, era uma prática restrita aos homens e poucas mulheres se arriscavam a compartilhar o palco como MCs. Até pouco tempo, quando circulavam por esses ambientes, as mulheres sofriam todo tipo de enfrentamento, como investidas sexuais e desmerecimento de suas criações. Em geral, eram convidadas para integrar crews como backing vocals ou como dançarinas. Corroborando esta linha, Cumberbatch (2001) afirma que as mulheres negras são sub-representadas na cena hip-hop, ainda que elas tenham erguido suas vozes, usado seus corpos e sua herança cultural, não apenas para combater estereótipos, mas para articular as complexidades da opressão e celebrar a diversidade identitária. Assim, observa-se que, embora a herança dos anos 1990 e 2000 tenha seus efeitos na realidade das rappers da nova geração, algumas desigualdades subsistem. No entanto, as jovens MCs não aceitam mais algumas práticas de seus pares e propõe um cenário de mudanças para a cultura hip-hop.

Assim, embora desde os anos 1990, o rap, tal como outros gêneros musicais, seja rotulado pelo sexismo e pela homofobia, realidade que permeia a estrutura da indústria musical ao longo das décadas, desde as letras até a instrumentação da música (Chapple \& Garofalo, 1977), a atividade das rappers vem marcando uma crescente força de empoderamento, autorepresentação e de diversidade. É a partir de uma nova guinada, no entanto, que para fins de organização temporal pode ser considerada uma quarta onda 
feminista ${ }^{213}$, que as mulheres, através do rap, vêm expressando massivamente suas experiências de persistente desigualdade, envolvendo o machismo e a misoginia, o patriarcado e a luta de classes, a heteronormatividade, o racismo, a pobreza e a violência. Assim, os anos 2000 , e mais fortemente a década de 2010 , foram o período de surgimento de um grande número de jovens rappers no Brasil e no mundo, cujas poesias buscavam denunciar as opressões cotidianas e a diversidade de ser mulher, desde a produção amadora, até a participação nos grandes mercados da música. Apesar de não ser um movimento homogêneo, mulheres já dedicadas ao rap inspiraram outras mais jovens a encontrarem seu flow e seu espaço no hip-hop. No Brasil, elas motivaram um número significativo ${ }^{214}$ de garotas de uma nova geração a expressarem suas demandas através das rimas.

Trazendo a discussão ao cenário contemporâneo brasileiro, observase que as jovens canalizam suas experiências de consumo musical, sobretudo do que é declamado por suas musas rappers, a fim de produzir as próprias letras, na tentativa de se autor representarem. Entre os vários discursos possíveis expressos no rap que cantam, há aqueles que demandam representatividade identitária. $O$ reposicionamento de suas identidades surge de enfrentamentos, sobretudo da necessidade de reconhecimento da ação cultural de alguns grupos sociais, como os coletivos de mulheres. Assim, com a consolidação de termos como "feminista" e "empoderamento feminino", hoje midiáticos, bem como o uso das redes sociais para conscientização e desenvolvimento de seus próprios ideais feministas, as rappers passaram a usar cada vez mais esses espaços para difundir suas rimas, denunciando a opressão vivida, transgredindo a linguagem no rap e algumas práticas na cultura hip-hop.

\footnotetext{
${ }^{213}$ Como apontaram em suas distintas trajetórias sobre feminismo e identidade da diferença, as autoras Chimamanda Ngozi (We Should All Be Feminists), nigeriana, a mexicana Glória Anzaldua e a pós-colonialista indiana Gayatri Spivak (Can the subaltern speak?), a própria noção de ondas históricas do feminismo precisa ser repensada, uma vez que remetem à ideia de centralidade do movimento em países desenvolvidos e seus reflexos nos países periféricos.

${ }^{214}$ Foram consultadas algumas listas em veículos especializados sobre rap ou sobre cultura musical. Quatro exemplos podem ser acessados em: 1) Rapologia https://raplogia.com.br/mulheres-no-hip-hop/; Hypeness https://www.hypeness.com.br/2018/10/5-minas-do-rap-nacional-e-5-rappers-gringas-paravoce-dar-o-play-no-spotify/; 3) Revista Glamour https://revistaglamour.globo.com/Lifestyle/Cultura/noticia/2017/12/8-novas-mulheres-dohip-hop-que-voce-precisa-ouvir-agora.html e 4) As Superlistas https://assuperlistas.com/2017/03/02/as-mulheres-no-rap-nacional/
} 
A partir de uma pesquisa ${ }^{215}$ que vem sendo realizada desde 2014 nas cenas rap da Região Metropolitana de Porto Alegre (RMPA), capital do Rio Grande do Sul (RS), resultam algumas reflexões sobre a participação das mulheres na produção de rap em uma zona específica do sul do Brasil (Mazer, 2018). Elas indicam pistas sobre as imbricações do regionalismo gaúcho na cultura hip-hop a partir do feminismo, sobretudo quanto ao protagonismo feminino. O enfoque dado está nas práticas de garotas ou de grupos de mulheres que compõem e performatizam rap, identificadas entre os mais de 200 sujeitos observados e entrevistados, homens e mulheres entre 18 e 35 anos de idade. Dentro da amostra e na realidade das cenas rap observadas, as mulheres ainda são minoria e estão sub-representadas, sobretudo quanto à performance como rappers. Apesar das dificuldades, as jovens MCs não deixam de protagonizar nas cenas e criar seus próprios espaços e processos produtivos, reconfigurando as relações de gênero na cultura hip-hop. Observa-se também a necessidade de se refletir sobre outras formas de ser gaúcho, sobre a representatividade da mulher e do negro na cultura gaúcha e sobre o regionalismo na cultura hip-hop.

\section{As MCs e o regionalismo gaúcho: rap, transformação e tradição}

A cultura gaúcha é caracterizada por suas particularidades e pela manutenção de seus ritos e tradições. Alguns desses elementos culturais são marcadamente tradicionais e regionalizados e, apesar da complexidade em se definir aquilo que representa uma cultura, podem ser identificáveis onde quer que sejam expressos, como o hábito de tomar chimarrão, por exemplo. Uma cultura regional reúne características socioculturais de uma zona específica dentro de um estado ou uma nação e algumas delas vão se cristalizando ao longo do tempo. Dito isso, o regionalismo, grosso modo, é a organização cultural conservada pelas tradições e passada adiante como representativa de determinada região. Sabe-se que as culturas e identidades regionais se constituem por processos históricos e são agenciadas por disputas culturais e políticas. A formação dos regionalismos no Brasil corresponde a um período de desigualdades nas relações de produção desde a República Velha (Oliven, 2004). Como movimento nacional, originou-se nos

\footnotetext{
${ }^{215}$ A pesquisa inicial investigou as práticas de consumo musical expandido (Mazer, 2018) entre jovens participantes da cultura hip-hop, o que envolve a produção e o consumo de rap na Região Metropolitana de Porto Alegre. Outra pesquisa, pós-doutoral, iniciada em 2018, vem colocando foco nas questões identitárias, refletindo sobre as hibridações entre regionalismo gaúcho e cultura hip-hop.
} 
processos intelectuais político-literários do final do século XIX no Brasil. Tem como expoente a publicação do "Manifesto Regionalista", por Gilberto Freyre, em 1926 (DaMatta, 2004). Tal como obedecem à elaboração e à preservação de valores tradicionais regionais, colaboram para constituir a cultura de uma nação e constituir a imagem de um sujeito regional autêntico, generalizado. De tal forma, o regionalismo reflete ou expressa valores, costumes ou tradições, assim como também se refere à tendência de considerar exclusivamente os interesses (políticos, culturais) particulares de uma região.

O regionalismo gaúcho é o conjunto de elementos vivenciados e naturalizados como próprios da cultura gaúcha, ou seja, aquela produzida pelos habitantes dos campos rio-grandenses, sobretudo a zona da Campanha, ou dos pampas (Brasil-Uruguai-Argentina). Tem origem ainda no século XIX, com o Regionalismo Literário (1860), fortalecendo-se no Movimento Tradicionalista Gaúcho, o MTG (1940) e, mais recentemente, no Nativismo (1980), um movimento predominantemente musical que propôs uma renovação estética, adequando as tradições a uma temática mais urbana e contemporânea (Jacks, 1998). Sabe-se que todas essas correntes tiveram origens elitistas, ainda que o MTG propusesse a incorporação de hábitos e ritos do campo. Mas, depois de uma década, o Nativismo deixou de ser essencialmente musical, passando a integrar todas as classes em todo o estado do Rio Grande do Sul, um fenômeno social de apropriação de elementos do tradicionalismo no cotidiano.

Já o Tradicionalismo gaúcho busca, desde sua criação, zelar por costumes e tradições, preservar lendas e hábitos, além de criar centros regionalistas de manutenção cultural, os CTGs (Centro de Tradições Gaúchas), hoje existentes em todo o Brasil e até em outros países. Entre as investidas do tradicionalismo está a manutenção da tradição musical, com uma série de restrições quanto a gêneros e instrumentos que poderiam ser incorporados na criação da música gaúcha, ainda que exista uma ampla gama de definições para isso. Da mesma forma, a composição do sujeito autêntico da cultura gaúcha está baseada em uma "regionalização universalista" (DaMatta, 2004) que exclui historicamente os negros e as mulheres. O mito do gaúcho (homem, branco, lutador, de bombachas com seu mate) como representante de um povo se edificou sobre múltiplas etnias, excluindo o negro [a mulher] e o índio dessa concepção (Oliven, 1996, grifo nosso). Na sociedade gaúcha contemporânea, esse mito vem sendo 
questionado por demandas de representatividade popular. Apesar de haver uma identificação com a cultura gaúcha, a negritude e o protagonismo feminino não são reconhecidos pelo tradicionalismo, e por isso mesmo eclodem demandas por representatividade cultural, sobretudo no hip-hop.

Aos poucos, as manifestações de rappers pela diversidade na representação dos gaúchos vêm se tornando mais midiáticas. Mas na cultura midiática gaúcha, segundo Grijó (2012, p. 52), “(...) devido a uma forte imigração europeia, a trajetória dos afrodescendentes foi colocada em segundo plano pelas elites locais, num fenômeno de invisibilidade". Essa tensão vem sendo retomada nas letras de rap e no cotidiano dos e das rappers, em produções midiáticas independentes que recolocam a representatividade identitária em questão, o que está fortemente conectado com o modo de produzir a cultura hip-hop.

Atualmente são discutidas as múltiplas possibilidades de ser gaúcho e o que isso representa cultural e politicamente, o que reflete na cultura hiphop. Sobretudo porque é através da representatividade que os hip-hoppers, em sua diversidade, adquirem condições para reivindicar e edificar uma realidade mais inclusiva. A apropriação do tradicionalismo por parte dos rappers é um dos disparadores das reivindicações por representatividade, que tem como resultante a identificação com um rap regional, autenticamente gaúcho, em um duplo movimento: por um lado os e as MCs rimam para valorizar sua comunidade de origem, sua periferia e sua negritude, contestando a invisibilidade negra na história oficial do Rio Grande do Sul e incorporando novos modos de fazer rap, por meio do compartilhamento da cultura global e regional. O outro lado dessa moeda é que a visibilização do hip-hop e das cenas rap são formas de dar a conhecer muitas vozes abafadas pelo modo de ver a cultura tradicionalmente.

Negligenciada na história oficial, assim como nas representações culturais e midiáticas que se fizeram do gaúcho (Kaiser, 1996; Grijó, 2012), a juventude negra passa a enxergar-se como agente da mudança demandada. E são as mulheres as protagonistas dessa nova história. Sua ação se dá a partir de práticas socioculturais, iniciadas no reconhecimento de suas identidades e refletidas em suas produções culturais - letras de rap, videoclipes, performances, novos negócios da música, etc. 
Apesar das mudanças propostas, após quase três décadas do surgimento de musas feministas no rap, a formação universal e generalizante do que é ser mulher e ser rapperainda aparece superficialmente nas questões relacionadas à cultura hip-hop, enquanto as ações e rimas das MCs relatam a necessidade de aprofundamento sobre diversidade e inclusão da mulher. Por disputarem espaço com os MCs homens, muitas rappers expõem em suas letras o urgente desejo de serem ouvidas, de fazerem seu rap. Por isso mesmo é que algumas de suas demandas são mais abrangentes, globais, incluindo o termo mulheres em uma posição universalizante na linguagem de suas produções. Seria uma resposta ao que McRobbie e Garber (2006) compreendem como "apagamento sistemático" das mulheres como protagonistas da história, sobretudo em culturas juvenis. Como se sentem excluídas dos processos produtivos, elas afirmam em alto e bom som a capacidade de rimar, de improvisar, de serem MCs, de modo geral, sem recorrerem necessariamente às especificidades de suas realidades. Isso fica ainda mais acentuado quando observada a cultura gaúcha contemporânea. De perto, a relação entre tradicionalismo e hip-hop revela nuances identitárias nas formas de ser uma mulher pertencente à cultura hip-hop, particularidades das rappers em constante diálogo com a cultura regional gaúcha, pois, como dito, elas foram historicamente excluídas como protagonistas da história cultural do estado.

No hip-hop, as demandas por diversidade na representação do gaúcho podem ser encontradas no modo como os símbolos regionais são apropriados para a composição de letras de rap e na realização de audiovisuais, como videoclipes, videocyphers, e ainda na adoção de nomes para faixas e álbuns. Alguns exemplos são os álbuns "Êra Êra", de Nitro Di, que tem participação de rappers mulheres, e as faixas "Tradição dos Pampas" e "Guerreir@s”, de Negra Jaque e "Rap de gaúcha”, do Hard Queens Crew, presente no álbum Junção das Gurias/Rap 4 Love. É também na incorporação de elementos da cultura gaúcha que podem ser apontadas algumas das fronteiras culturais relacionadas ao regionalismo e ao tradicionalismo gaúcho nas cenas rap. Isso em razão de que alguns aspectos da identidade cultural gaúcha conflitam com o contexto do hip-hop. Assim os e as hip-hoppers se identificam com o regionalismo e o tradicionalismo, ao passo que criticam em suas rimas a falta de diversidade nas representações culturais e midiáticas dos gaúchos. 


\section{Fronteiras e hibridismos culturais: mulheres na visão}

Ao assumirem elementos consolidados da cultura regional nas letras, videoclipes e outros produtos do rap, as rappers estão compartilhando da identidade gaúcha, ao mesmo tempo em que reivindicam sua representatividade como mulheres, negras e hip-hoppers. Criando rap com expressões como "rap de gaúcha", "sou gaudéria", utilizando imagens de estátuas de próceres do Rio Grande do Sul, localizadas em pontos turísticos, de jovens tomando o chimarrão em cuias, do sol se pondo no rio Guaíba, que banha a capital, Porto Alegre, vestindo trajes e peças típicas, como as alpargatas, e outros símbolos, elas colocam foco na complexa relação entre uma cultura de rua, de periferia, como o hip-hop e as tradicionais formas de representar a cultura gaúcha.

$\mathrm{Na}$ linguagem empregada, definem-se como guerreiras e gaudérias, referindo-se a si mesmas como lutadoras, ao enfrentarem as dificuldades cotidianas. Essa expressão, muito associada ao mito do gaúcho, é herança de religiões de matriz africana praticadas na região, como a Umbanda e o Candomblé, já que muitos dos orixás, suas divindades, são representados por guerreiros. Ademais, usam expressões como "guerra", "luta" e "batalha", presentes nas letras com a temática do enfrentamento, já consolidada na cultura hip-hop. Tais expressões aludem igualmente a um importante momento histórico no Rio Grande do Sul: a Revolução Farroupilha, cujos feitos heróicos são resgatados pelo "tradicionalismo" e pelo "regionalismo" gaúcho. Recorrem também à expressão "representar", referindo-se à posição de agência no hip-hop e na cultura regional, um modo de legitimar suas identidades e culturas híbridas presentes na cultura do Rio Grande do Sul.

As identidades não são uma essência, são um posicionamento (Hall, 1996), conjuntos de qualidades distintivas de grupos ou indivíduos, operadas, de acordo com Hall (1996), segundo dois sentidos: o primeiro indica como a cultura unifica as pessoas a partir da identificação de referências, estabelecendo uma cultura partilhada. $O$ segundo mostra que as identidades estão em constante mutação, "pontos instáveis de identificação ou sutura, feitos no interior dos discursos da cultura e da história" (Hall, 1996: 70). Assim, as cenas rap estudadas estão imersas em um processo dialético: têm forte influência global e nacional, mas igualmente são penetradas pelo regionalismo gaúcho, enquanto reconfiguram as representações da cultura regional. 
Sabe-se que a música tem o poder de criar um tipo particular de autodefinição, um lugar específico dos indivíduos em sociedade, em um processo de inclusão e exclusão constante (Frith, 1987). Portanto, uma identidade cultural pode, através da música, por exemplo, estar vinculada tanto ao sentido de pertencimento, como referência identitária, quanto a uma organização específica de heterogeneidade e desigualdade, em uma determinada sociedade (Müller, 2003). Ocorre que "o primeiro elemento de toda identificação é seu caráter relacional: ao mesmo tempo que estabelece um nós, define um eles." (Grimson, 2000: 29). Observa-se que a produção regional das rappers bascula entre o pertencimento a uma identidade cultural consistente e a quebra de estereótipos, em uma tensão constante.

São fronteiras demarcadas em uma metrópole, através de marcadores culturais urbanos, tais como a linguagem, as identidades de gênero, de raça/etnia e de classe, os pertencimentos de classe e território e as vinculações a distintas estéticas e gêneros musicais, com seus símbolos, processos de desterritorialização e reterritorialização, operações de agenciamento e de disputa, não necessariamente dispostos em uma zona de fronteira geográfica. De modo que a concepção de fronteiras aqui empregada não se limita ao entendimento de barreiras ${ }^{216}$, mas, se manifesta através de pontos de encontro ou 'zonas de contato' (Burke, 2006). Pesavento (2002) defende que, antes de serem marcos físicos ou naturais, as fronteiras são simbólicas. O não reconhecimento do outro colabora para erguer fronteiras culturais, já que o conceito opera "com princípios de reconhecimento que envolvam analogias, oposições e correspondências de igualdade, em um jogo permanente de interpenetração e conexões variadas" (Pesavento, 2002: 36). Para a autora, as fronteiras culturais "remetem à vivência, às socialidades, às formas de pensar intercambiáveis, ao ethos, valores significados contidos nas coisas, palavras, gestos, ritos, comportamentos e idéias" (Pesavento, 2002: 36). A fronteira se constrói a partir de diferenças, se baseia em identidades e alteridade, joga com essas circunstâncias no desenvolvimento de outras culturas. O "embaralhamento" de fronteiras, em vez de fazer o sentido de pertencimento se reduzir, mobiliza tensões ainda bastante vinculadas aos

\footnotetext{
216 Apesar disso, não se pode ignorar que o gaúcho é um ser essencialmente fronteiriço, seja por sua inserção no cone sul latino-americano, seja por sua característica de comunicar seus traços culturais mais marcantes a qualquer espaço por onde circule, ou ainda pela forte relação entre a cultura regional gaúcha e a indústria cultural e as inserções midiáticas do perfil do gaúcho, o que se deve, em parte, à existência de uma rede midiática regional (Jacks, 1998).
} 
territórios de desenvolvimento de uma cultura (Oliven, 2006). A manifestação cultural globalizada não eclipsa as questões e produções locais. Ao contrário, a circulação mundial torna a cultura local/regional mais importante que nunca (Oliven, 2006). É nessas bordas que ocorrem conflitos entre o espaço de dentro e o de fora; entre um sujeito e outro, entendendo que o espaço é o lugar da prática sociocultural (Certeau, 1994).

A música é um elemento artístico que expressa tensões criativas. Notadamente, um dos conflitos nas cenas rap da região é a constituição das identidades de matrizes africanas e de origens feministas. Em confronto com a cultura gaúcha, o tradicionalismo, o regionalismo se erigem diante das representações sociais e midiáticas das cenas rap e da cultura hip-hop, fronteiras culturais estabelecidas historicamente que pouco a pouco são reveladas nos raps que retomam as batidas de tambores e a presença de guerreiros da espiritualidade afro. Outro ponto de conflito, mas que igualmente contribui para a multiculturalidade regional é a apropriação de gêneros e instrumentos musicais do tradicionalismo no rap. Um gênero musical pode ser encarado a partir de seu caráter de autenticidade ou de hibridação e não há motivos para advogar pela autenticidade do "rap gaúcho", ou da música tradicional da cultura regional, sobretudo quando observada a riqueza dessa mistura. Distintos gêneros musicais são acionados, juntando as tradições musicais. Há diversos exemplos de raps criados na região que apresentam esse caráter híbrido, mesclando ao rap aos gêneros tradicionais gaúchos, como o xote, a rancheira, o bugio e a milonga. Num plano mais teórico, o hibridismo é o modelo explicativo da identidade (Canclini, 1988; 2015) e da multiculturalidade como o âmbito sociocultural latino-americano. As identidades são como narrativas que se constroem e reconstroem entre os diversos atores sociais, híbridas, dúcteis e multiculturais (Canclini, 2015). Por isso, a ruptura de algumas dessas fronteiras culturais a partir das identidades reivindicadas se dá em um plano primitivo, tais como as demandas das rappers por participação na cultura hip-hop, ou pela legitimação do rap que produzem. Isso não significa que as rupturas propostas não sejam fundamentais para a construção de novas narrativas culturais.

Algumas ações das MCs ao longo dos últimos anos vêm causando mudanças nas práticas dos hip-hoppers e resultando no empoderamento das rappers, através da criação de coletivos, de crews de mulheres, de batalhas 
de rimas, de feiras temáticas, de empreendimentos comerciais e do financiamento coletivo de álbuns e shows. Em 2014 começaram a surgir batalhas de rima pela região. Ainda que o conceito de batalhas remonte às origens do rap, na região estudada não havia registro de batalhas de sangue e de conhecimento até 2011. Na verdade, a diferença entre elas só se tornou mais acentuada a partir do crescimento no acesso à Internet pelos organizadores das disputas. Vale ressaltar que apenas duas batalhas são reconhecidas por existirem desde aquele ano: a Batalha do Mercado, criada e organizada por Aretha Ramos, uma produtora cultural e ex MC, e a Batalha do Parque Germânia. Em 2018, mais de uma centena de batalhas já acontecia na região. Esse crescimento acelerado se justifica por uma cultura de lazer impulsionada pelo hip-hop, desenvolvida em uma realidade de dificuldades no acesso cultural, carente de políticas públicas para educação, para o trabalho e do direito à cidade. Outro fenômeno relacionado às batalhas é o surgimento de duelos exclusivos para garotas. Criada em 2015, a Batalha das Monstras é considerada a primeira disputa desse gênero na região. Logo, outras surgiram trazendo como principal mudança a substituição de rounds de sangue, mais agressivos, por duelos de conhecimento, sobre temas escolhidos para as rimas, e até mesmo por saraus de poesia. Isso porque as mulheres participantes consideram que versos que desvalorizam os oponentes são apenas mais um exemplo da cultura patriarcal e machista. Elas se negam a declamar letras e poesias que desvalorizem seus concorrentes, tais como injúrias sobre a sexualidade, a aparência, a inteligência, a classe, etc.

Outro agente de mudança é a articulação política contra a desigualdade social, o machismo e o racismo. Desde 2014 vem crescendo o interesse das hip-hoppers por movimentos pela democracia e a favor dos direitos humanos. Isso se traduz em maior participação em manifestações políticas, como na atuação em campanhas eleitorais, pelo cumprimento de direitos, passeatas de reivindicação de direitos, na letra das músicas, posicionamentos nos perfis e postagens em redes sociais. Com a vitória do candidato de extrema direita, Jair Bolsonaro, nas últimas eleições presidenciais (2018), o engajamento às causas das minorias através de rimas e de ações populares se tornou ainda mais evidente. Outro episódio ligado ao aumento das manifestações foi o assassinato da vereadora Marielle Franco. Negra, lésbica e ativista pelos direitos humanos, Marielle vem sendo invocada 
como inspiração para versos que celebrem a interseccionalidade feminista. Também é notório o envolvimento de rappers e de líderes comunitários ligados aos partidos de esquerda, sobretudo ao Partido dos Trabalhadores brasileiro. As mulheres também estão na dianteira da criação de feiras e festivais musicais conectados a questões políticas, como Mestres de Cerimônias, produtoras, artistas, cantando seus raps de protesto, ou MCs de batalhas.

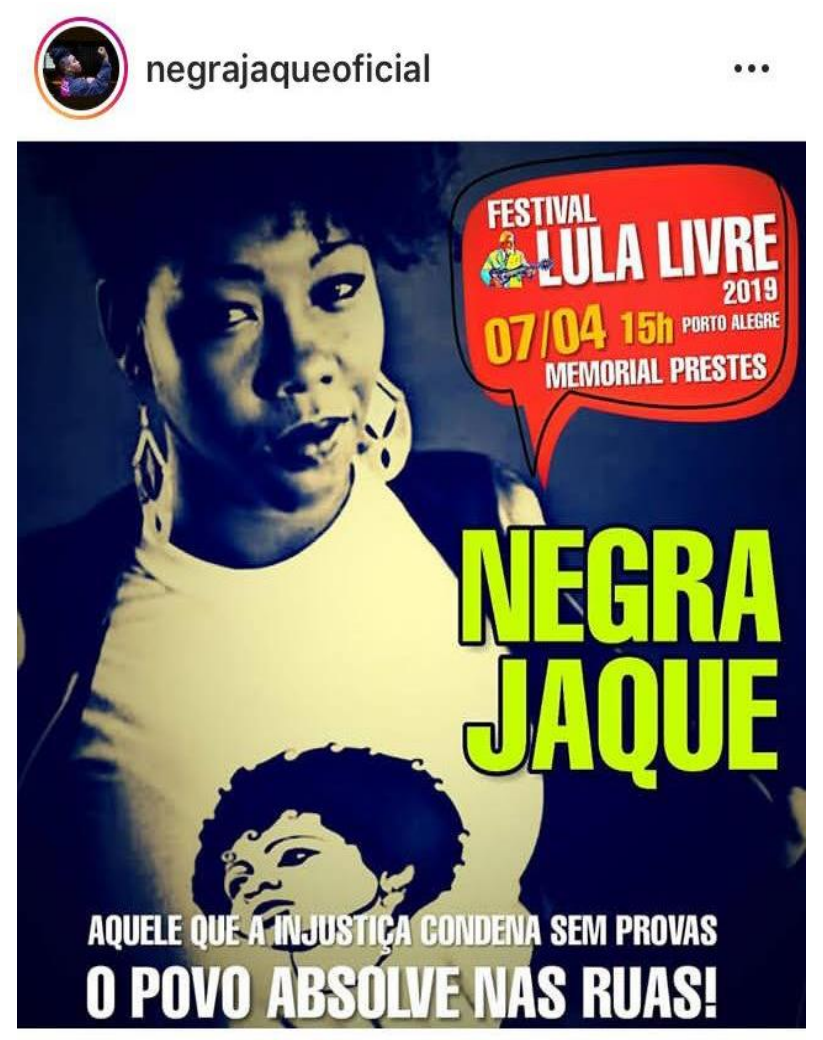

Figura IV.5.1: A rapper Negra Jaque convida seus seguidores na rede social Instagram para um festival musical, cuja temática reivindica a libertação do ex-presidente Lula

Fonte: Instagram.

\section{Algumas considerações finais}

O estudo revelou que, através do rap, as mulheres participantes da cultura hip-hop estão cada vez mais envolvidas em reflexões sobre feminismo e práticas transformadoras, expondo ideias feministas, sobretudo na música que produzem. Suas performances e letras apontam contextos de opressão e demandas por maior participação cultural e direitos sociais, enfrentando fronteiras seculares. Frente a isso, buscam meios alternativos de circular nas cenas musicais, (re)territorializando espaços urbanos, antes restritos aos homens, organizando ações comunicativas em rede para a criação e difusão do rap, tecendo formas próprias para o lazer e propondo temáticas mais 
inclusivas no hip-hop. Dessa forma, elas buscam se integrar socialmente, ampliando as possibilidades de representatividade, assumindo elementos da cultura regional gaúcha no trabalho que desenvolvem. Igualmente, tendem a se diferenciar em sociedade, indicando as desigualdades vividas por meio da apropriação de tecnologias de comunicação e do desenvolvimento de novas práticas culturais. O desejo da representatividade é manifestado nas performances artísticas, nas ações culturais coletivas, nas letras de rap, nas produções audiovisuais, etc. Suas rimas apontam ainda as diferenças entre ser mulher e ser mulher negra rapper. É um exercício que expõe demandas de um feminismo interseccional ainda carente de fortalecimento. Outro forte indicador social expresso nos versos é a demanda por inclusão nos palcos, estúdios, praças de batalhas de freestyle, em que as mulheres ainda enfrentam a postura legitimadora de homens que definem o que é rap e quem pode praticá-lo.

É importante destacar que as desigualdades entre homens e mulheres seguiram pautando as letras de rap ao longo das décadas, sobretudo em países com índices de desenvolvimento humano medianos ou baixos, como o Brasil. Além disso, algo persiste entre as musas noventeiras e as rappers da nova geração: a maioria delas ainda começa a fazer rimas através de crews majoritariamente masculinos, ou conhecem as batalhas de rima e freestyle a convite de seus amigos ou namorados homens. Por isso a criação de eventos de rap produzidos por mulheres é tão importante para a transformação de suas práticas culturais. De forma equivalente, o domínio nas rotinas produtivas reflete em modos de ser MCs mais livres, já que os contratos com as grandes gravadoras já não são (há tempos) a única maneira de figurar entre rappers de sucesso.

Há uma variedade de letras de rap circulando em formatos audiovisuais, amadores ou não, publicados nas redes sociais, que buscam enunciar a relação conflituosa entre ser negro e ser mulher, principalmente como membro da cultura hip-hop. Elas são formas de expressar as trocas que ocorrem nas bordas de fronteiras culturais. o texto procurou explorar esses conflitos, apontando também os avanços e mudanças culturais proporcionadas através da cultura hip-hop em intersecção com o feminismo. Da mesma forma, buscou-se contribuir para a temática ao investigar a hibridação de gêneros musicais, cujos produtos reforçam o sentido de pertencimento à cultura e ao território, seja a cultura gaúcha, seja a de rua, 
de periferia, ou a cultura black. Ademais, o texto convida a refletir sobre outras formas de ser gaúcho, sobre a representatividade da mulher e do negro na cultura gaúcha e sobre o regionalismo na cultura hip-hop. Espera-se que cada vez mais o rap feito junto à cultura regional gaúcha seja difundido, ganhe espaços midiáticos e possa resultar em mais direitos e igualdade para as rappers.

\section{Referências Bibliográficas}

Burke, P. (2006). Fronteiras culturais dos primórdios da Europa moderna. In: Schüler, Fernando L. \& Barcelos, M. (Orgs.). Fronteiras: Arte e pensamento da época do multiculturalismo (pp. 146-151). Porto Alegre: Sulina.

Canclini, N. G. (1988). Narciso sin espejos - La cultura visual después de la muerte del arte culto y el popular. In: Calderón, Fernando (Org.). Imágenes desconocidas. La modernidad en la encrucijada postmoderna (pp. 49-57). México: CLACSO.

Canclini, N. G. (2015). Culturas híbridas. Estratégias para entrar y salir de la modernidade. México, DF: Debolsillo.

Certeau, M. de (1994). A invenção do cotidiano: 1. Arte de fazer. Petrópolis: Vozes.

Chapple, S., \& Garofalo, R. (1977). Rock ' $n$ ' roll is here to pay. The history and politics of the music industry. Chicago: Nelson-Hall.

Cumberbatch, R. (2001). Sisters with voices: women making music in the Hip-hop scene. Winnipeg: University of Winnipeg.

DaMatta, R. (2004). Nação e região: em torno do significado cultural de uma permanente dualidade brasileira. In Schüler, F. L.; Bordini, Maria da Glória (Orgs.). Cultura e identidade regional (pp. 19-30). Porto Alegre: EDIPUCRS.

Frith, S. (1987). Towards an aesthetic of popular music. In Frith, S. (Org.). Taking Popular Music Seriously: Selected Essays (pp. 257-274). Hampshire: Ashgate.

Grimson, A. (2000). El puente que separó dos orillas: notas para una crítica del esencialismo de la hermandad. In Gonzales, J. A. \& Grimson, A. (Comp.). Fronteras, naciones e identidades: la periferia como centro. (pp. 201-231). Buenos Aires: CiccusLa Crujía.

Grijó, W. P. (2012). Que negro é esse na cultura da mídia? Uma análise a partir do contexto gaúcho. Revista da ABPN, 4 (8), jul-out. 2012, pp. 52-67.

Guerra, P. (2017). 'Just Can't Go To Sleep'. D.I.Y. cultures and alternative economies from the perspective of social theory. Portuguese Journal of Social Sciences, 16 (3), September, pp. 283-303.

Guerra, P. (2018). Raw Power: Punk, DIY and underground cultures as spaces of resistance in contemporary Portugal. Cultural Sociology, 12(2), pp. 241-259.

Hall, S. (2001). A identidade cultural na pós-modernidade. Rio de Janeiro: DP\&A. 
Hall, S. (1996). Identidade cultural e diáspora. Revista do Patrimônio Histórico e Artístico Nacional, IPHAN, pp. 68-75.

Jacks, N. (1998). Mídia nativa. Indústria cultural e cultura regional. Porto Alegre: Editora da Universidade/UFRGS.

Kaiser, J. (1996). CTG de Negros: O racismo no tradicionalismo gaúcho. In Leite, I. B. (Org). Negros no Sul do Brasil: invisibilidade e territorialidade (p. 248-261). Florianópolis: Letras Contemporâneas.

Mazer, D. (2018). Racionalidades do consumo musical: práticas culturais juvenis na cena rap porto-alegrense. Porto Alegre: Universidade Federal do Rio Grande do Sul. Faculdade de Biblioteconomia e Comunicação. Programa de Pós-Graduação em Comunicação.

McRobbie, A. \& Garber, J. (2006). Girls and subcultures. In Hall, Stuart \& Jefferson, T. (Eds.). Resistance through rituals. Youth subcultures in post-war Britain (pp. 209-222). Londres: Routledge.

Müller, K. M. (2003). Mídia e fronteira: jornais locais em Uruguaiana-Libres e Livramento-Rivera. São Leopoldo: Unisinos.

Oliven, R. G. (1990). O maior movimento de cultura popular do mundo ocidental: o tradicionalismo gaúcho. Cadernos de Antropologia. Porto Alegre: Universidade Federal do Rio Grande do Sul, nº. 1, pp. 5-46.

Oliven, R. G. (1996). A invisibilidade social e simbólica do negro no Rio Grande do Sul. In: Leite, I. B. (Org). Negros no Sul do Brasil: invisibilidade e territorialidade (p. 13-32). Florianópolis: Letras Contemporâneas.

Oliven, R. G. (2004). Cultura brasileira: retratos de uma identidade. Reis, Elisa P. Zilberman, Regina (Orgs.). Retratos do Brasil (pp. 109-124). Porto Alegre: EDIPUCRS.

Oliven, R. G. (2006). Fronteiras culturais. In: Martins, Maria H., \& Chiappini, L. (Orgs.). Cone Sul: Fluxos, representações e percepções (pp. 207-233). São Paulo: Hucitec.

Oware, M. (2009). A "man's woman"? Contradictory messages in the songs off emale rappers, 1992-2000. Journal of Black Studies, 39 (5), pp. 786-802.

Pesavento, S. J. (2002). Além das Fronteiras. In: Martins, Maria Helena (Org.) Fronteiras culturais. Brasil-Uruguai-Argentina (pp. 35-39). São Paulo: Ateliê Editorial.

Reddington, H. (2003). 'Lady' punks in bands: a subculturette?. In The post-subcultures reader (pp. 239-251). Muggleton, D., \& Weinzierl, R. (Orgs.). Oxford: Berg.

Reddington, H. (2012). The lost women of rock music. Sheffield: Equinox.

Rose, T. (1994). Black Noise. Rap music and black culture in contemporary America. Hanover, NH: University Press of New England. 